\title{
Portrayal of Women from Stereotype to Empowered in Film Studies
}

\author{
Poonam Pichanot ${ }^{\mathrm{a}}$, Dr Nidhi Bhatnagar ${ }^{\mathrm{b}}$ \\ ${ }^{a}$ Research Scholar, Arts and Humanities Sangam University, Bhilwara \\ ${ }^{\mathrm{b}}$ Associate Professor, Arts and Humanities, Sangam University ,Bhilwar \\ achouhanponam89@gmail.com, ${ }^{b}$ nidhi.bhatnagar@sangamuniversity.ac.in
}

Article History: Received: 10 November 2020; Revised 12 January 2021 Accepted: 27 January 2021; Published online: 5 April 2021

\begin{abstract}
Nowadays, without films, we can't really imagine contemporary India society. Although this is Unable to conceptualize a film without a 'story.' A film must 'tell' and 'show' Story, unravelling layer by layer, introducing the magic of the silver narrative on the screen. The stories rooted in culture are praised by the viewer. More so, if they are widely acknowledged in oral or written form, right from the beginning, there has been an indelible connection between literature and films. The policy begins with depictions of women protagonists in mainstream Bollywood films. This topic is considered appropriate because women are a large part of the population of the country and their on-screen representation is thus critical in deciding the promotion of current stereotypes in the country in the society. The paper begins with a discussion on the field of feminist film criticism and how mainstream Hindi Cinema has restricted itself to defined sketches of womanhood. Cinema has limited itself to established sketches of femininity.
\end{abstract}

Keywords: Cinema, popular, media, women, Bollywood, movies, stereotypes, feminist, Empowered, patriarchal

\section{Introduction}

Film studies discuss the problems of truth and representation by making an initial assumption and continuing logically from it. This premise is that there's sense to all representations. The key aspect of cinematic representation is defined by the word mise-en-scene (also mise-en-scene). The first step in learning how films create and represent context is mise-en-scene. It's a French word, and it means what was put on the scene or puton stage (Shendurnikar 8). The word mise-en-scene defines everything in the filmed image, literally everything: it is the descriptive totality of what you see in a single image of the film. Many programs integrate film studies with media and television studies, gaining accepted expertise from all parts of visual production (Sibal5).A wide range of curricula have developed to examine critical techniques used in film due to the ever-growing dynamic of film studies. A shift away from Hollywood productions in the 1950s turned cinema into a more creative independent effort.t was the emergence of the theory of the aureate, which asserted film as the vision and art of the maker, that in the 1960 s prompted film studies to become genuinely considered academically worldwide. In his writings on Alfred Hitchcock, film critic Robin Wood claimed in 1965 that Hitchcock's films featured the same complexities as Shakespeare's plays. The first 'story film' released in 1912 was Pundalik. It was based on a Marathi play and parts of play were filmed directly. However, this failed to provide much of an impetus to regular film-making, until the first 'talkie' Alam Ara (1931) hit the screen. While it was largely inspired by the histrionics of Parsi theatre, it created a new language, the 'language of cinema 'As such, the dependence of cinema on literature came to be cemented. Paradoxically, right from the beginning, whether in the case of silent cinema or the first talkies (1931), there is strong evidence to show that inspired by the literary medium the cinematic medium has had the potential to carve out its distinct style, grammar, motifs -- in short, to make its 'language' visible. Moreover, such dependence on literature did not cripple the film medium; rather it helped it to grow from strength to strength, and in the process to fine tune its own language. (Shendurnikar 3). The film themes based on the literary works of the authors from various parts of India had distinct regional flavour. For instance, the dialogues of Mirza Ghalib written by Rajendra Singh Beedi brought in the nuances of Urdu spoken in Shahabad (Old Delhi) to greatly enhance the aesthetic flavour of this biopic. Likewise, Bimal Roy, a prominent filmmaker adapted several literary works and created a series of meaningful cinema which conveyed the message of social transition and universal brotherhood. Some of his well-known films are Do Bigha Zameen, Parineeta, Biraj Bahu, Devdas, Sujata, and Bandini. All these films were based on renowned literary works. He influenced several filmmakers such as Satyen Bose, Gulzar and Phani Mazumdar to name but a few. Films such as Phir Bhi, Sara Akash, Uski Roti, Maya Darpan, and Duvidha were off-beat films based on contemporary literature. (Sibal 5). The unconventional themes chosen for their films and trueto-life presentation style earned them appreciation in 
India and abroad.There are some movies that have surpassed our vision to becoming the biggest hits we've ever seen. They've done direction to the books and inspired many more. Some of examples are like:

\section{A. Jaws (1975)}

A big hit was Peter Benchley's book. For weeks, it remained a bestseller. The story of the film was marginally better, however. There were way too many romantic subplots in the book that the film happily paid less attention to and concentrated more on the excitement of the film and the beast that consumes man. So, plus one for the film.

\section{b Mrs Doubtfire (1993)}

About Robin Williams. Enough justification to choose the book over the film. His comedic timing and brilliant execution of the character of an old maid add an extra spunk to the story. A winner with a hands-down.

\section{c The Color Purple (1985)}

Steven Spielberg created a stellar adaptation of the novel by Alice Walker and one that, in terms of both plot and character, is highly faithful to the novel. This is a real achievement because Spielberg depends on his actors to express through their performance much of the emotional material, while we are privy to the inner thoughts and feelings of Celie in the novel. The amazing performances from the cast make this film a must-see

\section{d Sense and Sensibility (1995)}

The 1995 film adaptation of Ang Lee's Jane Austen novel by Emma Thompson changes many of the characters in subtle but successful ways to make them more attractive to contemporary sensibilities while retaining in the original book the complexities and tensions. The outcome was an Oscar for Best Adapted Screenplay for Thompson and a film that remains one of the novel's finest modern versions.

The transfer of a work or plot, in whole or in part, to a feature film is a film adaptation. While often considered a kind of derivative work, academic scholars such as Rober Stam have recently conceptualized film adaptation as a dialogical process. Using a novel as the basis of a feature film is a popular type of film adaptation. On-fiction (including journalism), autobiography, comic books, scriptures, plays, historical sources and other films are other works translated into films. In nineteenth-century Europe, adaptation from such disparate sources has been an omnipresent tradition of filmmaking since the earliest days of cinema.

\section{Statement Of Problmem:}

\section{a Status of Women into Society}

In view of the primary argument that the representation of women and men in Bollywood films represents the subordinate role of women in India, it is imperative to look through a historical lens at the status of women in India. It is said that "sometimes the life of a woman also tells a nation's story" (Misra868). Throughout the history of India, women have been exposed to abuse and harmful practices. Anda seldom considered autonomous person. Taking into account India's psycho-socio-politico-economic-cultural past, Jugal Kishore Misra (2006) notes that she is at best a shadow, a picture of domestic doulas, a prisoner of the comfortable concentration camp, in other words of the "house," robbed of her own ontology/autonomy, being and being (Misra868). The position and status of an Indian woman in society is defined by her bodily functions of providing men with sexual pleasure and reproduction, carrying the offspring of the man (Mathur 55). An Indian woman, to put it plainly, is not equivalent to an Indian man.(Sibal5). Like Kanchan Mathur in most Indian families (2008) Compared to their brothers and other male members of the family, daughters are viewed as liabilities and treated as inferior. On the other hand, sons are celebrated and idolised; a traditional Hindu wedding blessing is " may you be the mother of a hundred sons" (Mathur55). Mathur explains that virginity and chastity are virtues at the root of the socialisation pattern. Where the notions of courage and 'macho' are rooted in the child's upbringing as the right to influence abuse, on the other hand, daughters are supposed to be chaste, respectful and 'good' at the receiving end of violence (Mathur 55)., Being a 'good woman' means upholding the family's reputation, keeping the 'culture of silence' and, last but not least, being obedient and sacrificing. During the girl's upbringing, she must obey certain behavioural expectations that include "how to speak, how to dress, or for whom to dress up, how to sit and behave in the presence of males, her mobility is restricted to the extent that very often movement outside the home has to be with prior permission." (Mathur55). Mathur adds that, women, consciously and/ or unconsciously, are socialised and discipline themselves to be the bearers of familial and social honour - a symbol of tradition (Mathur 255) Through their works, literary authors and filmmakers have sought to illustrate women's positions and identities in family and culture. In past centuries and present times, these pieces illustrate the role of women very well. There is also ample knowledge and statistics available in the form of research publications and magazines on various interrelated factors. Comparison between the status of women in the past and that of modern women, their 
accomplishments across the globe, their lives after marriage, various opportunities available to them, the world's social and cultural attitude towards them, to name a few. This involves many areas of discussion. All of this so clearly portrays one part, time and time again.

\section{b Status of Women in Old Society.}

In previous ages, men dominated society, while females were secondary to them. At the family level, women had very little or no opinion, and males were entirely in charge of all decisions. A woman was assumed to be owned by a man (Gull119-120). Great academic achievements and formal jobs were high for men, while women performed family duties and bore the burden of housework. A patriarchal and impoverished society with an inhumane caste system led to women's severe suffering in various parts of the globe. They were (and are being mistreated) inside and outside their homes (Chitnis \& Wright 1317). Indian law explicitly states that women have equal rights with men and are legal citizens of the country Stuff taken into account, most of them have ill health and malnutrition. This, especially for pregnant and nursing women, creates a major problem. If women ever think of themselves first, society makes them feel guilty about it in some way. They need to complete the highest priority household chores (academically, financially, etc.). Historically, many women were uneducated, and now many of them have schooling, but most of it is not sufficient.

\section{Comparision Of Old And New Status Of Women In Society}

For several years in the past, the role of women was a topic of serious controversy. This includes various burning issues for girls and women in education, maternal health, economic empowerment of women, and the role of women in family, community, politics, and more. The role of women in society is a critical factor in determining the development of any culture.(Sibal5). Speaking of India's culture, Manu, the great law-giver, said, 'where women are worshipped, the gods live.' A man can not engage in any religious rite with excellence in Hinduism without his wife's participation. Wives are called 'Ardhangani' (the better half), and it is impossible to carry out any critical work without them. As women have always been a burden, the conventional notion that no good can come from a girl being born. These thinkers are completely unable to grasp the horrors of a world without women (Gull:120). If girls are born, they do not receive the same commitment and care as boys would While our law firmly guarantees free primary education for anyone up to 14 years of age, only about 39 percent of women in India will attend primary schools. Though quite slowly, they are actually changing in favour of women (Chitins \& Wright1324). Indian women began their journey on the path taken by the women of India more than eighty years ago to the Western world. The role of females in shaping modern India has been phenomenal. The Indian sub-continent gradually emerged as a strong nation as women started to play important roles in the development of this country, its culture and economy. The change in the role of women from the past to the present is worth noting. Women are now considered to be the forces that grow a nation. They are able to make a perfect balance between their household and professional lives. Indian women have decorated high offices and prestigious positions in the long list of many others, such as President (Mrs. Pratibha Devi Singh Patil), Prime Minister (Mrs. Indira Gandhi), Speaker of the Lok Sabha (Mrs. Meera Kumar), first woman, IAS (Esha Basant Joshi), the first woman, and IPSS, the first woman (Kiran Bedi). Article in the Interdisciplinary Studies Academic Review Journal. With the advent of technology, women have the most ability to dominate the planet in various ways. Kalpana Chawla, Sunita Williams (astronauts), Aishwarya Rai Bachchan, Priyanka Chopra (Miss Universe and actresses), Saina Nehwal, Sania Mirza (players), Sunidhi Chauhan, Shreya Ghoshal (singers), Sushma Swaraj (former Minister of Foreign Affairs), Tessy Thomas (defence researcher), and Indira Hinduja (scientist and doctor) (singers) are some examples of women achieving great success to name a few. Some of the world's most influential women are Oprah Winfrey (first African-American global billionaire), Angelina Jolie (actress and humanitarian) and Melinda Gates (co-chairperson, Bill and Melinda Gates Foundation). A recent addition is New Zealand's present PM, Jacinda Ardern, who in a short span of two years has helped her nation hit enormous heights!

\section{Reveiw Of Literature}

Cinema, which is a significant socio-cultural force, is a media facet. "Today, it can be seen as one of the most effective forms of visual communication. (Turner, 1999:3) Indian cinema has undergone many changes since Independence, including a transformation from classic mythological blockbusters to famous "Bollywood zed" remakes of Hollywood films. In the success of individual films within the Indian film industry, women have also played an important role. Nevertheless, their roles have shifted overtime, from relying on their male colleagues to quite individually moving the story forward. (Fram1) It is important to recognize today's significance of Indian cinema in the world before referring to the changes.(Sibal7)

\section{Women In Film Studies}

Women in movies is a non-profit organization dedicated to fostering equal opportunities for women Supporting women's artistic ventures and expanding and improving women's portrayals in all facets of global 
representation. Bollywood women have become uni-dimensional protagonists; it's good or bad, black or white. No shades are in between. Jain, J., \& Rai, S. (2009). 2009. Movies and Feminism. The dichotomy has been emphasized in popular films that distinguish between the heroine and the vamp, the wife and the other woman. Religion and mythology also inspired films, where female characters, those who could not do wrong, were seen as the epitome of morality and values. After independence, the image of women as Sita was frequently evoked in many movies. Hindi cinema, through the values of loyalty and obedience to the husband, successfully institutionalized patriarchal ideals. In films like Dahej (1950), Gauri (1968), Devi (1968), Pati Parmeshwar (1988) depicted women as passive, submissive wives as ideal figures and martyrs for their own families (1970). Although the patriarchal traditions in these films were criticized, they were implicitly patronized in the sense that the wife of the victim refuses to leave her husband's house in the midst of intense physical and emotional violence by leaving the marital house only at the time of her death. (2009). Films and Feminism. (Misra, . 'In the 1970s, there were women in different working positions in Hindi cinema (Jaya Bachchan as a knife sharpener in 'Zanjeer' and a singer in 'Abhimaan' and Hema Malini as a village tonga (horse carriage) driver in 'Shoaly'). The working woman vanished from the famous nineties blockbusters, with Indian women confined to the home frontier.

\section{Changes In The Status Of Women In The Film Studies}

The decade of the nineties in Hindi cinema was one which popularized the genre of family drama. There were many family films which became blockbusters and reinforced the patriarchal values of Indian society.(Sibal8)Realistic cinema varies from conventional cinema in the sense that its subjects derive inspiration from real life situations and real circumstances in society. Though, obviously, it may fall into the realm of conventional cinema, its approach and treatment of characters is more convincing than traditional cinema. It is interesting to look at some movies from this cinema brand, which is becoming popular among viewers. This style of cinema blends popular appeal and critical acclaim This form of cinema brings together popular appeal and critical acclaim. In this form of cinema, movies such as Black Friday (2004), Udaan (2010), No One Killed Jessica (2011), Once Upon a Time in Mumbai (2010), Akros (2010) etc. can be identified. Madhur Bhandarkar's films have been chosen for review for the purposes of specificity and clarification. The cinema of Bhandarkar is related to gritty realism. His films have tackled bold and unorthodox subjects such as women's violence, the cycle of poverty, organized crime, police and government. Corruption, celebrity and journalistic culture, big business ruthlessness and industrial espionage. There were female protagonists in several of his films. In Bhandarkar movies, women are typically seen as courageous and motivated women who lead lives on their own terms, make their own decisions, are rebels who do not comply with social norms and succeed in their respective professions.(cf. Sircar, 1995; Gokulsing \& Dissanayake, 1998; Kabir, 2001; Pendakur, 2003; Ganti, 2004),Prime Minister Narendra Modi launched the Beti Bachao Beti Padhao Scheme on January 22, 2015, which aims to raise awareness and increase the effectiveness of providing welfare services for girls. When it comes to feminine empowerment, Indian cinema is not far away. Here are the best and most memorable characters that have perfectly embodied the strength of women.

\section{a List of selected films based on respective literary texts}

Shivani Shivaji Roy of Mardaani: Rani Mukherjee's portrayal of a fierce cop in Mardaani perfectly showcases the true strength of a woman. The character is based on a real-life cop who solved several child trafficking cases. Shivani Shivaji Roy not only single-handedly beat up some of the baddest criminals but held her own against the evil doers. The perfect mix of strength and respect, Roy is an inspiration. (Shivani 5)

Gita of Swadesh: When most of the youth in villages seem to be migrating to urban cities for better jobs and opportunities, the simple character of Gita (played by Gayatri Joshi) from Swades sets an example of an empowered woman who can make her own decisions (Shivani7)

Michelle in Black: Rani Mukherjee's character Michelle as the visually and hearing-impaired protagonist in the movie Black is one of the most powerful portrayal of a physically handicapped person in Indian cinema. The relationship of Michelle with her aging teacher (Amitabh Bachchan) and how she helps him to rediscover life is very liberating, inspiring and shows the true strength of a woman. (Shivani5)

Radha of Mother India: A mother's character has always been depicted as sacrificing, loving and all-forgiving - the one who would go extra mile to do the best for her children. But Radha (Nargis) in Mother India played a challenging, different and strong character who killed her own son when he became an outlaw.

Old movies to new movies reflecting the Development Of the women. Some of the Example are: DevdasDevdas, of Sharad Chandra Chattopadhyay's 1917 novel, Othello Omkara and Macbeth- Maqbool of William Shakespear,and there are many more films which were based on novels who represent the strength of women in this new era. It was also chosen as India's entry for the Academy Award for Best Foreign Language Film that year.Pinjar (2003): The period drama directed by Chandra Prakash Dwivedi was based on a Punjabi novel of the 
same name by Amrita Pritam set during Partition. The film, starring Urmila Matondkar and Manoj Bajpayee, made slightly over ₹ 4 crore in box office collections and also won the National Award for Best Feature Film on National Integration. It is not possible to study all the novels from some of the prominent writers have been chosen for the further studies

\section{Objectives:}

- To find out the gender Discrimination.

- Representation to explore Woman as an Empowered Entity.

- To Identify the Characteristics of Modern Women in Film Studies.

- Explore the Gender Discrimination discourse in Film Studies.

- The trend of using language for women in the Films.

\section{Research design :}

Methodology used in this study is analytical. In this work already available facts an information and it is used to critically evaluate the portrayal of women in films. Here since movies are taken up which has been written by Indian Authors, the conclusion is made on the basis of the analysis of all the films separately. The films are critically observed and representation of the women in stick into an account. The development of the portrayal of the females from stereotype to empowered females has been seen though the various discourse used in the films.

\section{Conclusion}

Bollywood films, through their representation of women and men, represent the subordinate status of women in India, in view of the study of gender roles in the selected Bollywood films based on novels and the key point of the paper is that most Bollywood films appear to portray hero as 'active' and women as 'passive.' It is important to illustrate the role of the state in the creation of these gender roles. It is difficult to draw a standardized conclusion about the representation of women.(Nudrat21) Given that women are not a homogeneous group in India, they belong to various faiths, castes, classes, socio-economic status and have different kinds of aspirations and desires as a consequence of which they lead different lives., it is improper to say that women on Indian silver screen have been depicted in an identical manner. Of course, the picture has to be responsive to the group to which it belongs. Films must also be attentive to the background in which female characters are located. This is evident in the disparities in the representation of men and women in Bollywood movies. Men's representation as 'new' is not challenged, unlike women.(Sibal5). The equilibrium of 'new' and 'traditional' applies only to women. It can then be said that the conflict between the representation of women and the debate on women's empowerment growth is, at a broader level, a contradiction between the women's empowerment development approach and the version of the 'ideal Indian woman' by the Indian state..

\section{References}

Article in Scholarly Research Journal for Interdisciplinary Studies - March 2018 DOI: 10.21922/srjis. v5i43.11253

Ahmed, S. Akbar (1992). 'Bombay Films: The Cinema as Metaphor for Indian Society and Politics'.

Modern Asian Studies 26, 2 (I992), pp. 289-320. Great Britain.

Burra, R. (ed.) (1981). 'Film India: Looking Back 1896-1960'. The Direc torate of Film Festivals, New Delhi.

Laura Mulvey (1988), 'Visual Pleasure and Narrative Cinema'. In Con stance Penley (ed), Feminism and Film Theory, New York: Routledge.

Misra, Vijay (2006). 'Bollywood Cinema: A Critical Genealogy'. Asian Studies Institute, Victoria

Deconstructing Gender Roles in Bollywood Films: Through Women's Empowerment Development Discourse:Nudrat Raza - 44410(2015)

Monica Motwani (1996), The Changing Face of the Hindi Film Heroine, G Magazine Online.

Singh, Indubala (2007). Gender Relations and Cultural Ideology in Indian Cinema: A Study of Select Adaptations of Literary Texts, Deep \& Deep Publications.

Joseph, A., \& Sharma, K. (1994). Whose News? The Media and Women 'e Issues (pp. 21). N

Agarwal R. (2014), Shifting Roles of Women: Through The Lens Of Bollywood, Vienna:10th International Academic Conference

Banaji S. (2006), Reading 'Bollywood': The Young Audience and Hindi Films, New York

Agarwal R. (2014), Shifting Roles of Women: Through The Lens Of Bollywood, Vienna: 10th International Academic Conference

Al Jazeera (2014), The Stream - Women through a Bollywood lens, Al Jazeera, [Online] - Available at: http://goo.gl/Nr8WrW - [Accessed on June 10 2015] 
Article in the Interdisciplinary Studies Scholarly Research Journal. March 2018 DOI: 10.21922/srjis. v5i43.11253) 